\title{
Fruit-Derived Polyphenol Supplementation for Athlete Recovery and Performance
}

\author{
Joanna Bowtell ${ }^{1}\left[\right.$ D $\cdot$ Vincent Kelly ${ }^{2,3}$ (i)
}

Published online: 22 January 2019

(c) The Author(s) 2019

\begin{abstract}
Polyphenols are characterised structurally by two or more hydroxyl groups attached to one or more benzene rings, and provide the taste and colour characteristics of fruits and vegetables. They are radical scavengers and metal chelators, but due to their low concentration in biological fluids in vivo their antioxidant properties seem to be related to enhanced endogenous antioxidant capacity induced via signalling through the Nrf2 pathway. Polyphenols also seem to possess anti-inflammatory properties and have been shown to enhance vascular function via nitric oxide-mediated mechanisms. As a consequence, there is a rationale for supplementation with fruit-derived polyphenols both to enhance exercise performance, since excess reactive oxygen species generation has been implicated in fatigue development, and to enhance recovery from muscle damage induced by intensive exercise due to the involvement of inflammation and oxidative damage within muscle. Current evidence would suggest that acute supplementation with $300 \mathrm{mg}$ polyphenols $1-2 \mathrm{~h}$ prior to exercise may enhance exercise capacity and/or performance during endurance and repeated sprint exercise via antioxidant and vascular mechanisms. However, only a small number of studies have been performed to date, some with methodological limitations, and more research is needed to confirm these findings. A larger body of evidence suggests that supplementation with $>1000 \mathrm{mg}$ polyphenols per day for 3 or more days prior to and following exercise will enhance recovery following muscle damage via antioxidant and antiinflammatory mechanisms. The many remaining unanswered questions within the field of polyphenol research and exercise performance and recovery are highlighted within this review article.
\end{abstract}

Joanna Bowtell

j.bowtell@exeter.ac.uk

$1 \quad$ Sport and Health Sciences, College of Life and Environmental Sciences, University of Exeter, Exeter EX1 2LU, UK

2 School of Human Movement and Nutrition Sciences, University of Queensland, St Lucia, QLD, Australia

3 School of Exercise and Nutrition Sciences, Queensland University of Technology, Brisbane, QLD, Australia

\section{Key Points}

Fruit-derived polyphenols have antioxidant and antiinflammatory properties and so can enhance exercise performance, since excess reactive oxygen species generation has been implicated in fatigue development, and enhance recovery from intensive exercise due to the involvement of inflammation and oxidative damage within muscle.

Consumption of $\sim 300 \mathrm{mg}$ polyphenols an hour prior to exercise may enhance endurance and repeated sprint performance, most likely due to improved muscle perfusion.

Supplementation with $>1000 \mathrm{mg}$ polyphenols per day for 3 or more days prior to and following exercise will enhance recovery from exercise-induced muscle damage. 


\section{Introduction}

Many sports and activities involve strenuous eccentric muscle contractions and explosive movements that can induce muscle damage to varying degrees depending on the intensity and duration of activity as well as the training status of the individual. Prolonged endurance events such as marathons and ultramarathons, triathlons and Ironman also place extreme demands upon muscle and can also induce ultrastructural damage and muscle soreness. It is therefore important to identify effective strategies for supporting rapid recovery between intensive training sessions especially during pre-season, when multiple sessions are completed in the same day, and between matches particularly in a tournament setting. The purpose of this paper is to provide an overview of the growing evidence that fruit-derived polyphenol supplementation enhances recovery from intensive exercise with or without muscle damage, and may enhance exercise performance.

\section{Polyphenols}

Polyphenols are ubiquitous within plants, where they are produced as secondary metabolites and involved in a diverse range of critical processes including growth, pigmentation, pollination and resistance to pathogens and environmental stressors [1]. They are characterised structurally by two or more hydroxyl groups attached to one or more benzene rings, and can be classified into four main families: lignans, phenolic acids, stilbenes and flavonoids. Stilbenes consist of $2 \times 6$ carbon aromatic rings joined by a 2 -carbon bridge with a double bond and the parent compound is resveratrol. Flavonoids consist of two aromatic rings linked through a 3-carbon chain, usually in the form of an oxygenated heterocycle; and can be sub-divided into a range of sub-classes on the basis of the degree of oxidation of the oxygenated heterocycle, including: flavanols, flavonols, flavanones, flavones, isoflavones and anthocyanidins. Tannins are oligomers and polymers of flavonoids, and can be grouped into condensed tannins (proanthocyanidins) and hydrolysable tannins (procyanidins). Table 1 provides a brief summary of example compounds and key dietary sources of the different polyphenol families. The taste and colour characteristics of fruits and vegetables are strongly influenced by the polyphenol content. Both the quantity and variety of polyphenols present are determined by the plant species, growing conditions sometimes termed terroir (sunlight, water and nutrient availability, temperature), post-harvest processing, and transport and storage conditions [2-4]. There is therefore considerable variability in the polyphenol content of foods on the supermarket shelves, and in the many polyphenolrich fruit-derived supplements that are now commercially available. For research purposes, in particular, it is therefore essential that such natural variation can be accounted for by testing each batch for polyphenol content and composition.

Polyphenol absorption and metabolism is highly complex, not least because of the many thousands of different polyphenol compounds present within plants, their possible interactions within the food matrix [5] and their conjugation to form a large number of different metabolites upon absorption. In addition, with the exception of flavanols and proanthocyanidins, polyphenols are present as glycosides, i.e. conjugated with sugar moieties within the plant. Anthocyanins can be absorbed intact (e.g. cyanidin-3-glycoside), but many other polyphenols must be hydrolysed to split the sugar group (glycone) from the polyphenol (aglycone) before absorption [6]. This process occurs either via lactase phloridzin hydrolase in the brush border of the small intestine epithelial cells or via cytosolic $\beta$-glucosidase within the epithelial cells, which requires uptake of the polar glucosides into the epithelial cells via sodium-dependent glucose transporters [7]. The aglycones can then be absorbed into
Table 1 Dietary sources of the different polyphenol families and sub-families

\begin{tabular}{lll}
\hline Polyphenol family & Example compounds & Dietary source \\
\hline Stilbenes & Resveratrol & Grapes \\
Lignans & Enterodiol & Seeds, whole grains, legumes \\
Phenolic acids & Cinnamic & Caffeic acid-coffee \\
& Benzoic & Gallic acid-tea \\
Flavonoids & Epicatechin, & Cocoa \\
Flavanols & Catechins & Green tea \\
Flavonols & Quercetin & Onions, apples, deep green vegetables \\
Flavones & Luteolin & Parsley and other herbs \\
Flavanones & Naringenin and hesperetins & Citrus fruits \\
Isoflavones & Genistein & Soy products, \\
Anthocyanidins & Cyanidin, malvidin, delphinidin & Cherries and berries \\
Proanthocyanidins & B-type dimers & Cocoa \\
Procyanidins & Ellagitannins & Pomegranate \\
& Gallotannins & Mango \\
\hline
\end{tabular}


the circulation; however, they are subject to conjugation, resulting in the formation of sulfate, glucuronide and/or methylated metabolites both within the epithelial cells and in the liver [8]. A large proportion of polyphenols are not absorbed within the small intestine and continue to the colon where they are acted upon by enzymes present within the microbiota to release aglycones that then undergo ring fission to produce bioavailable metabolites such as phenolic acids and hydroxycinnamates [8]. These substances can be detected in the plasma some $12-48 \mathrm{~h}$ after polyphenol ingestion. Ingestion of a single polyphenol can give rise to many different metabolites, which was clearly shown in an elegant investigation where participants consumed $500 \mathrm{mg}$ of ${ }^{13} \mathrm{C}$ labelled cyanidin-3-glycoside, and 17 different labelled metabolites were detected in plasma over the subsequent $48 \mathrm{~h}$ [9]. Fruits and vegetables and fruit-derived polyphenol supplements contain a blend of polyphenols, and thus the pharmacokinetics and metabolism after ingestion of whole foods or fruit-derived supplements are even more complex. There is also a high degree of inter-individual variation in bioavailability partly dictated by differences in the gut microbiome [10]. To date the majority of studies that investigated the effects of polyphenol supplementation on either recovery from intensive exercise or exercise performance have not quantified plasma phenolic metabolites after supplementation, except for several studies employing cocoa or chocolate supplementation in which plasma epicatechin and catechin concentrations were measured [11, 12]. Whilst a number of published studies have measured acute changes in plasma phenolic metabolites or the parent compounds after single doses of Montmorency cherry [13], blueberry [14], blackcurrant [15] and pomegranate [16], future work in this field should ideally quantify exercise performance outcomes alongside measurement of plasma phenolic metabolites.

\subsection{Effects of Polyphenol Supplementation}

Polyphenols possess radical scavenging properties related to their chemical structure. Phenolic hydroxyl groups can donate an electron to radicals and the polyphenol aromatic ring can then stabilise the resulting aroxyl radicals [17]. Polyphenols are also metal chelators and hence can reduce metal-catalysed free radical formation [18]. However, maximum plasma concentrations of conjugated and unconjugated polyphenols have been estimated to range from 0.1 to $22 \mu \mathrm{mol} \mathrm{L} \mathrm{L}^{-1}[19,20]$. When compared to the concentration of plasma urate $\left(150-450 \mu \mathrm{mol} \mathrm{L}^{-1}\right)$, which is also an important plasma compartment antioxidant, it seems unlikely that plasma phenolics are effective direct antioxidants in vivo. Many of the studies reviewed in this article have quantified changes in the debunked [21] plasma total antioxidant capacity (TAC) after polyphenol supplementation. However, TAC only quantifies the cumulative action of small molecule antioxidants present in plasma, and ignores the important contribution of intracellular enzymes such as superoxide dismutase, catalase and peroxiredoxin. This cannot therefore be regarded as a true measure of in vivo antioxidant capacity. The increases in TAC observed after polyphenol supplementation are likely to be almost entirely dependent upon changes in plasma urate related to fructose metabolism, and independent of changes in plasma phenolics [22]. There is now growing evidence that phenolics are able to upregulate endogenous antioxidant capacity via the $\mathrm{Nrf}$ 2/antioxidant response element (ARE) pathway. Nrf2 is a master regulator of the antioxidant response through the regulation of a wide range of antioxidant and phase II detoxification genes [23], and protects cells from stressors including reactive oxygen species (ROS), and dietary xenobiotics such as polyphenols [24]. Keap1 is a cysteine-rich protein that represses Nrf2 signalling by serving as a bridge between Nrf2 and ubiquitination ligase cullin-3, which is required for the ubiquitination of the protein and subsequent proteasomal degradation [25, 26]. Oxidative stressors or electrophiles induce covalent modification of Keap1 cysteine residues and therefore inhibit ubiquitination-dependent degradation and increase nuclear accumulation of Nrf2, resulting in increased synthesis of downstream endogenous antioxidants such as superoxide dismutase, catalase and peroxiredoxin [27]. Although dietary polyphenols are not present in sufficient quantity in vivo to contribute directly to antioxidant function as radical scavengers, phenolics will be converted to electrophilic quinones and hydroquinones upon exposure to ROS, which are then able to interact with Keap 1 and activate Nrf2 (for a review, see Huang et al. [24]). Paradoxically it seems that antioxidant effects of polyphenols arise from their pro-oxidant action after in vivo exposure to ROS, although much of the evidence for this is currently from in vitro work, and there is a need for human in vivo studies to verify this hypothesis. Polyphenols also seem to possess anti-inflammatory properties and have been shown in vitro to inhibit cyclo-oxygenase enzymes, COX1 and COX2 [28], to reduce NF-KB expression signalling [29] and to inhibit nuclear translocation of NF-KB [30].

In resting human studies, changes in plasma biomarkers of oxidative damage and inflammation support the antioxidant and anti-inflammatory effects of fruit-derived polyphenols including cherries [31], blueberries [32, 33], blackcurrant [34], pomegranate [35] and cocoa [36]. There is also consistent evidence that both acute and chronic supplementation with polyphenols improves vascular function, specifically endothelium-dependent vasodilation, which is nitric oxide (NO) dependent and measured in vivo as flowmediated dilatation (FMD). A meta-analysis of 42 cocoa studies found significant increases in FMD following acute (3.2\%) and chronic (1.3\%) supplementation, respectively [37]. A smaller number of studies have been performed to 
assess the acute or chronic effects of fruit polyphenols on FMD, and these have mostly utilised grape-derived polyphenols as well as pomegranate, chokeberry or blueberry. Rodriguez-Mateos et al. [14] showed that a range of blueberry polyphenol doses (0.3-1.88 g polyphenols) increased FMD in healthy men peaking at $1 \mathrm{~h}$ and this paralleled reduction in neutrophil nicotinamide adenine dinucleotide phosphate (NADPH) oxidase activity. This suggests that reduced superoxide production and hence decreased conversion of NO to peroxynitrite likely contributes to the increased vasodilation response by improving NO bioavailability.

A number of studies have also found improvements in endothelial-dependent vasodilatation after chronic supplementation with fruit polyphenols especially amongst study populations with impaired cardiovascular function (grape juice [38, 39], red grapes [40], grape polyphenols [41], grape seed [42], chokeberry juice [43]) or with low habitual fruit and vegetable intake (blackcurrant [44]). A meta-analysis revealed that after supplementation with a mix of flavonoids, the absolute mean difference in $\%$ dilatation was $\Delta 2.33 \%$ (based on 18 acute supplementation studies) and $\Delta 0.73 \%$ with chronic supplementation (based on 14 studies) [45]. The optimal dose identified was $500 \mathrm{mg}$ per day total flavonoids or $300 \mathrm{mg}$ per day of procyanidins.

The improvement in FMD in response to acute and chronic polyphenol supplementation is by definition a result of increased NO bioavailability, since FMD is NO dependent. These effects are likely achieved through a variety of synergistic mechanisms. There is evidence from in vitro studies that polyphenols induce endothelial nitric oxide synthase 3 (eNOS) activation via signalling through oestrogen receptor- $\alpha$ via $\mathrm{G}$ protein, extracellular-signal-regulated kinase (ERK) and phosphatidylinositide 3-kinase (PI3 K) pathways [46]. In addition, polyphenols have been shown to inhibit NADPH oxidase, one of the key sources of superoxide production [47], and to induce signalling through Nrf2, thus increasing endogenous antioxidant capacity [48], both of which will preserve NO bioavailability by reduced formation of peroxynitrite. In addition to the health benefits associated with these antioxidant, anti-inflammatory and vasoactive properties of polyphenols, they are also of relevance for exercise performance and recovery from intensive exercise.

\section{Fruit-derived Polyphenols and Exercise Performance}

\subsection{Rationale}

Exercise-induced fatigue has been extensively investigated, but the mechanisms remain controversial due its complex multifactorial nature and specificity to exercise mode, intensity and duration. Fatigue may relate to: (i) depletion of muscle fuel substrates such as phosphocreatine (PCr) or glycogen, (ii) accumulation of metabolic by-products such as ammonia and hydrogen ions, (iii) perturbation of ionic gradients between intra- and extracellular compartments thus interfering with action potential transmission, (iv) impaired excitation contraction coupling via altered calcium sensitivity and sequestration to the sarcoplasmic reticulum, (v) altered central drive due to afferent feedback from the exercising muscle conveying changes in the metabolic milieu (for a review, see Allen et al. [49]). The ability to regulate and co-ordinate the function of cardiovascular, respiratory, metabolic and neuromuscular systems is pivotal to ensure that the kinetics of substrate supply and waste product removal match the requirements of the specific exercise bout and thus performance is preserved.

Skeletal muscle is a net producer of reactive oxygen species from a variety of sources including the mitochondrial respiratory chain and enzymatic sources such as NADPH oxidase and xanthine oxidase [50]. Paramagnetic electron spin resonance experiments demonstrate that ROS generation increases with exercise intensity [51, 52]. ROS are important signalling molecules and have been implicated in contraction-mediated increases in muscle glucose uptake [53] and control of skeletal muscle blood flow [54]. For instance, Durand et al. [55] found that hydrogen peroxide caused vasodilation in exercising muscle. It appears that under conditions of low oxidative stress and redox balance, ROS promote optimal vasodilation and hyperaemia in exercising muscle. However, under conditions of oxidative stress or already disturbed redox balance, ROS generation during exercise impairs blood flow and vasodilatory capacity [56]. Ryanodine receptors are the major calcium release channel in the sarcoplasmic reticulum (SR), and due to the high number of cysteine residues in this protein, it is redox sensitive [57], as is SR Ca2 + ATPase activity. Excess ROS generation has been shown to impair calcium handling and sensitivity resulting in reduced contractile force development, thus impairing exercise performance [50, 58]. Additionally, group III and IV afferents are sensitive to ROS, so ROS production within exercising muscle will be sensed by the somatosensory cortex, which may result in altered efferent activity and central drive to the muscle, contributing to the development of central fatigue [59]. Therefore, during high intensity or prolonged exercise where ROS generation exceeds the antioxidant capacity and results in disturbed redox balance, it is plausible that antioxidant supplementation may counteract fatigue and enhance performance via enhanced perfusion of the exercising muscle, better maintained excitation-contraction coupling and central drive. There is some empirical evidence to support this view, since supplementation with antioxidants such as $N$-acetyl cysteine [60-62] has been shown to improve exercise performance. There is also evidence that 
acute (Table 2) or chronic (Table 3) supplementation with fruit-derived polyphenols is ergogenic for performance.

\subsection{Evidence of Enhanced Performance}

\subsubsection{Acute Polyphenol Supplementation}

Pomegranate has been a key ingredient in the majority of the relatively small number of studies in which the effects of acute polyphenol supplementation (single dose $<3 \mathrm{~h}$ pre-exercise) have been investigated either consumed singly [63-65] or in combination with green tea and grape polyphenols [66]. Consumption of $1 \mathrm{~g}$ of pomegranate extract [63] $30 \mathrm{~min}$ pre-exercise or a combined supplement of pomegranate, green tea and grape extract ( $290 \mathrm{mg}$ polyphenols [66]) consumed $1 \mathrm{~h}$ pre-exercise enhanced time to exhaustion whilst running at 90 and $100 \%$ of peak velocity achieved at $\mathrm{V}_{2}$ max, and peak and average power output during repeated cycle Wingate tests in recreationally active individuals, respectively. However, trained cyclists [64] and recreationally resistance-trained individuals [65] did not derive significant performance benefit from consumption of $1 \mathrm{~g}$ of pomegranate extract. Specifically, time to exhaustion at $100 \% \mathrm{VO}_{2}$ max workload was not enhanced by consumption of pomegranate $2.5 \mathrm{~h}$ pre-exercise either at sea level or at the equivalent of $1657 \mathrm{~m}$ altitude, despite a significant increase in oxygen consumption in the altitude condition after supplementation, and increased plasma nitrate concentration after pomegranate supplementation [64]. Similarly, bench and leg press repetitions to failure and average and peak power during $10 \times 6 \mathrm{~s}$ sprints were not significantly elevated by pomegranate supplementation (30 min pre-exercise), although confidence interval-based statistics indicated increased power output during the middle sprints, (S5 and 7 [65]) despite evidence of favourable vascular effects after supplementation, with elevated brachial artery diameter and flow post-exercise in the pomegranate condition [65]. Other polyphenol-containing supplements have also shown mixed results when used prior to exercise in an attempt to improve performance. Trained cyclists experienced modest improvements in end-sprint performance $1.5 \mathrm{~h}$ after ingestion of Montmorency cherry concentrate [67]. Recreationally active men also apparently derived ergogenic effects from supplementation with ecklonia cava extract [68] and a combined grape and apple polyphenol supplement [69], with increased time to exhaustion during a maximal incremental treadmill running test, and cycling at $70 \%$ maximum aerobic power, respectively. Conversely, consumption of $900 \mathrm{mg}$ cocoa flavanols $3 \mathrm{~h}$ pre-exercise did not significantly enhance cycling time trial performance in trained male cyclists [11].

Analysis of the limited published data currently available suggests that timing of consumption may also be an important factor, since in those studies where supplements were consumed within $1 \mathrm{~h}$ of exercise, ergogenic effects were evident, but where the supplement was consumed $>2 \mathrm{~h}$ prior to exercise, performance was not improved. Unfortunately, plasma phenolic concentrations were not measured in these studies; however, extrapolation from other studies (blueberry [70], Montmorency cherry [13], pomegranate [16], grape [71] and cocoa flavanols [72]) would suggest that elevations in plasma phenolics would be evident within 30 min of consumption with peak concentrations of simple phenolic metabolites likely within $1-2 \mathrm{~h}$ of ingestion. These changes presumably underpin the observed ergogenic effects, which are likely to involve inhibition of superoxideproducing enzymes such as NADPH oxidase [14], enhanced antioxidant enzyme activity [66] and vascular mechanisms $([63,65,66]$, see Sect. 3.3).

\subsubsection{Chronic Polyphenol Supplementation}

Chronic polyphenol consumption also seems to produce ergogenic effects for recreationally active participants and to a lesser extent for trained athletes. Consumption of oligomerized lychee extract for 30 days (200 $\mathrm{mg}$ polyphenols) enhanced running time to exhaustion at $80 \%$ heart rate maximum [73], and red grape skin extract for 6 weeks (1.17 $\mathrm{g} \cdot \mathrm{day}^{-1}, 220 \mathrm{mg}$ polyphenols [74]) improved 50-m swimming time trial performance in recreationally active participants. Blackcurrant powder (300, $105 \mathrm{mg}$ anthocyanins) consumption for 7 days ( $105 \mathrm{mg}$ anthocyanins) enhanced cycling time trial performance $(16.1 \mathrm{~km} \mathrm{[75])}$ and high-intensity intermittent running distance to exhaustion [76], and reduced fatigue index with repeated sprints in recreationally active participants $[77,78]$, and in trained individuals induced a small $(0.8 \%)$ improvement in repeated 4-km cycling time trial performance [79]. Braakhuis et al. [80] also found a possible improvement in 5-km time trial performance for faster female runners after 3 weeks' blackcurrant polyphenol supplementation (300 $\mathrm{mg}$ anthocyanins) during a period of intensified training, with evidence of performance decrement with vitamin $\mathrm{C}$ supplementation in this randomised crossover trial. However, 7 days of pomegranate supplementation (1800 mg polyphenols) did not enhance cycling time trial performance in trained male cyclists [81]. Nor did 2 weeks of dark chocolate supplementation (108 mg catechins and $88 \mathrm{mg}$ flavanols) enhance time to exhaustion at $90 \% \mathrm{~V}_{2}$ max in recreationally active men, despite elevated plasma free fatty acid concentrations and evidence of reduced exercise-induced oxidative damage (F2-isoprostanes and oxidised low-density lipoprotein cholesterol [82]).

For many of the studies it is not clear how long after the last polyphenol dose exercise was performed. In other words, it is hard to differentiate a chronic effect from the potential acute effects derived from supplementation within $2 \mathrm{~h}$ of exercise. All reported studies involved supplementation 


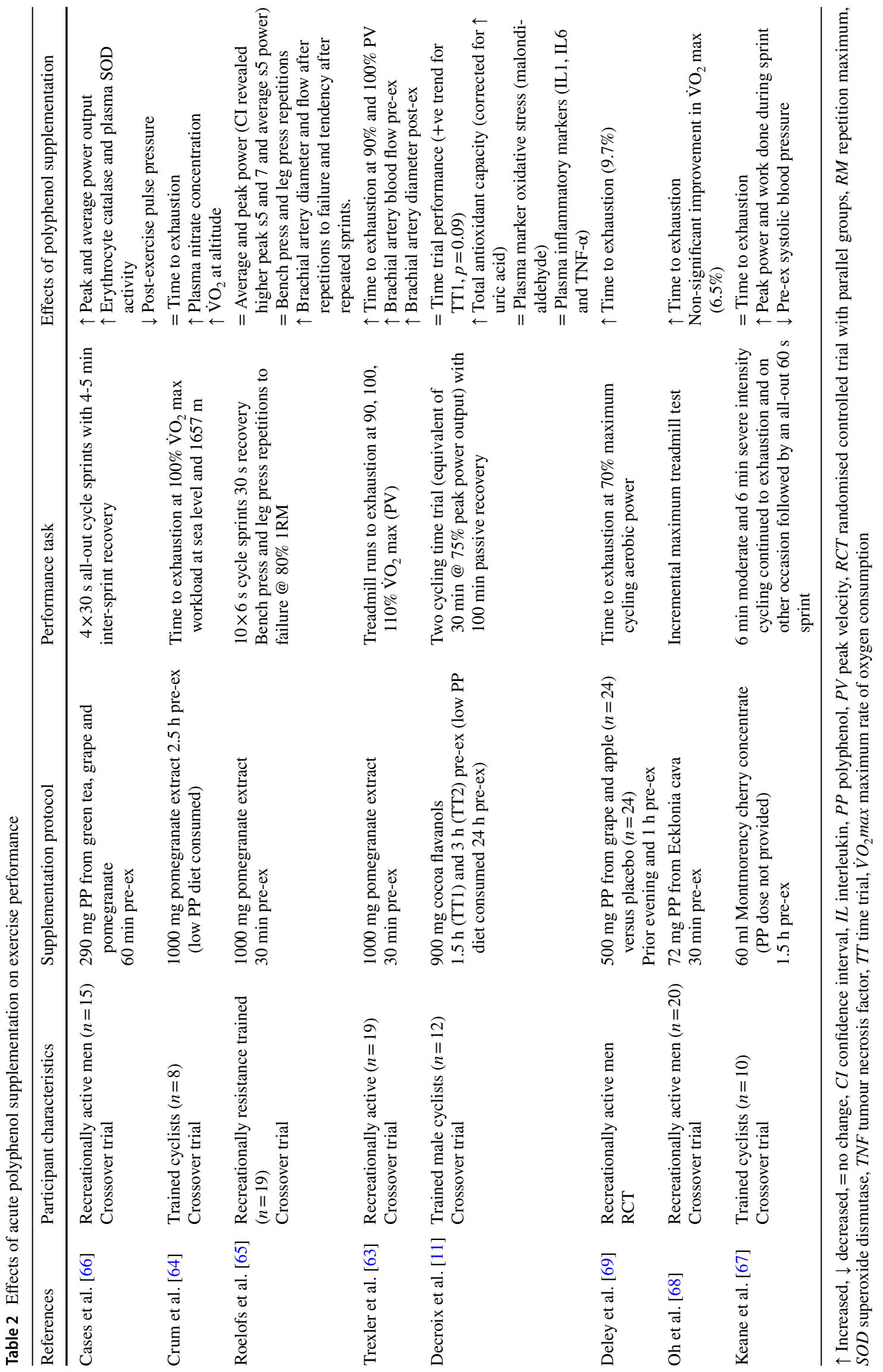




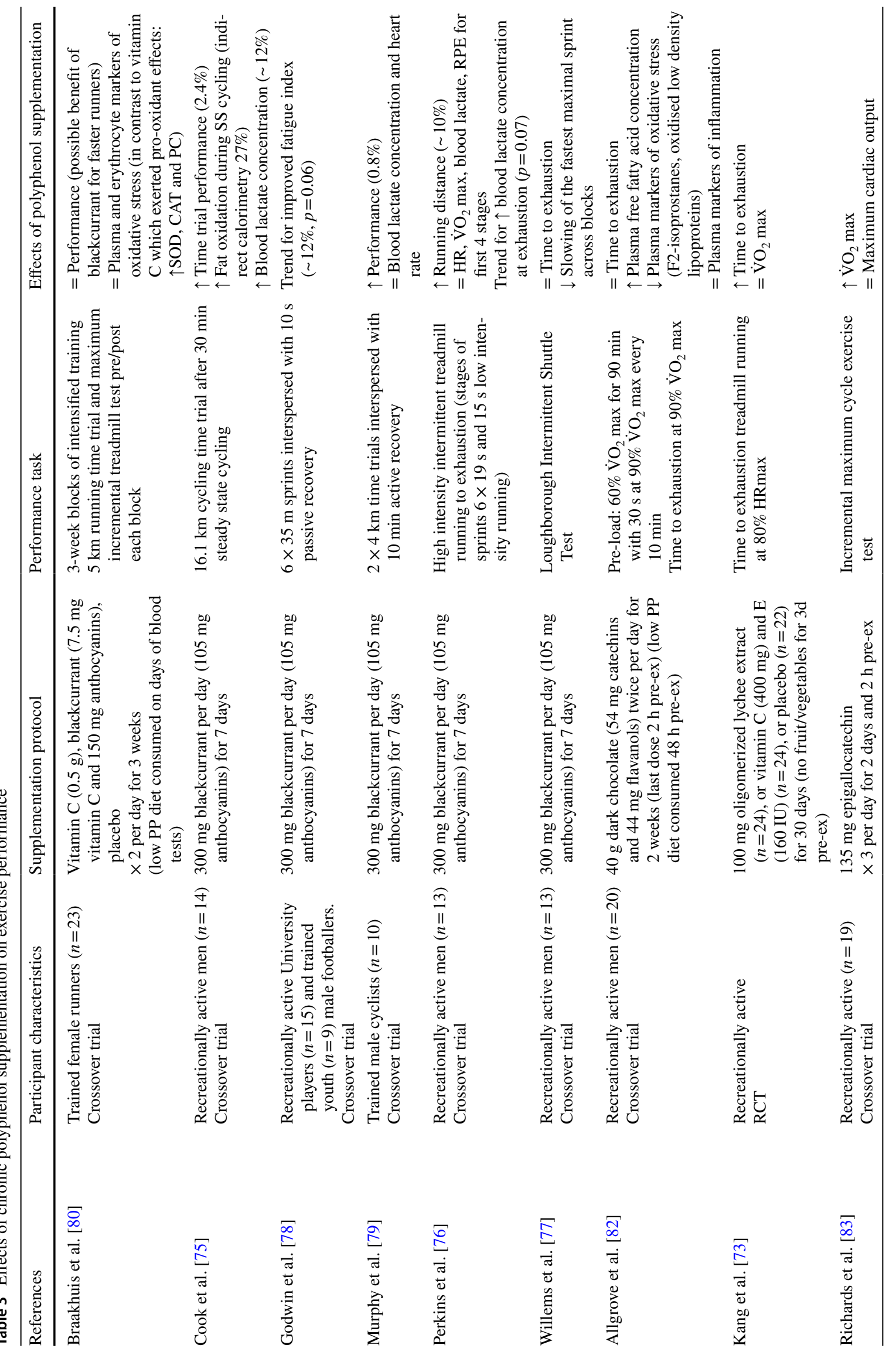




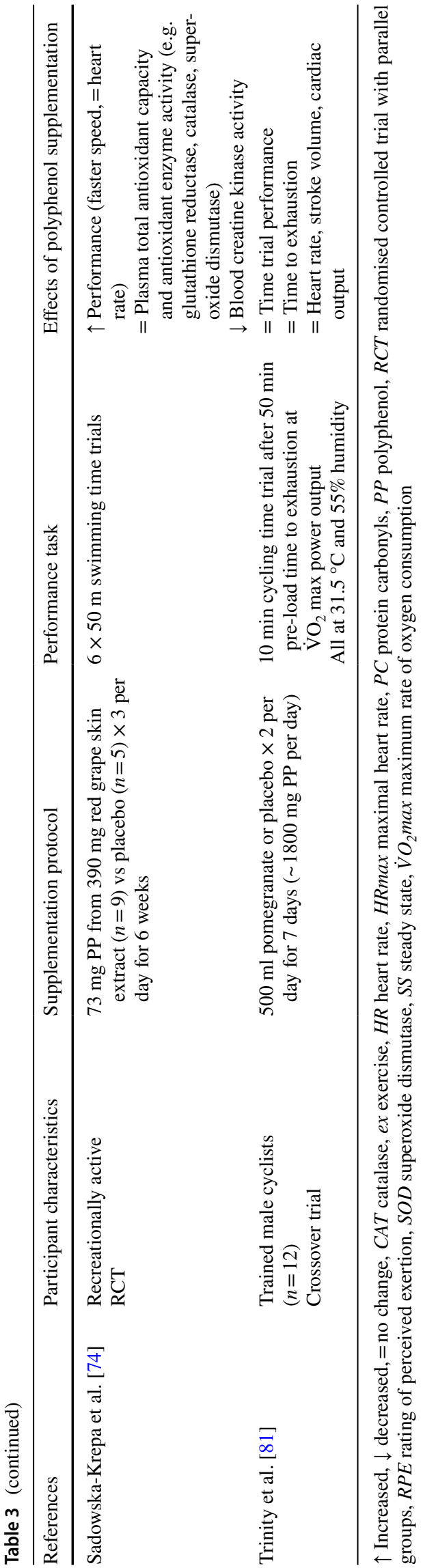

for $\geq 7$ days, which should provide sufficient time for changes in gene and protein expression to occur within tissue. However, to our knowledge there are currently no data available from studies that combine measurement of changes in muscle proteins in response to polyphenol supplementation with changes in exercise performance. From the available evidence, the most likely mechanisms appear to be reduced exposure to or increased capacity to degrade ROS and reactive nitrogen species (RNS) as evidenced by reduced markers of oxidative damage $[80,82]$ or increased antioxidant enzyme activity [74]. These responses seem to occur in parallel with enhanced vascular function possibly resulting in improved muscle perfusion and enhanced oxygen extraction [83].

\subsection{Mechanisms}

The conflicting findings across studies with regard to the effects of polyphenol supplementation are most likely due to the differences in research design including: the supplement composition, timing and dose of supplementation variation in the studied population, and performance tasks employed and therefore differences in the predominant processes contributing to fatigue development. The ergogenic effects of polyphenols seem to involve altered vascular function with augmentation of the measured increases in brachial artery diameter and blood flow after a 1 min occlusion, induced by pomegranate supplementation, which paralleled the ergogenic effects for performance [63, 65]. Similarly, Richards et al. [83] found that $\dot{\mathrm{VO}}_{2}$ max was enhanced by supplementation with green tea-derived epigallocatechin (EGCG) supplementation for 2 days ( $135 \mathrm{mg}$ three times per day) and a last dose $2 \mathrm{~h}$ pre-exercise. However, maximum cardiac output was not affected by EGCG, which therefore implies that the performance-enhancing effects were achieved via increased arterio-venous oxygen difference, i.e. improved oxygen extraction in the exercising muscle presumably coupled with better spatial distribution of muscle perfusion. Goncalves et al. [84] used nail-fold videocapillaroscopy of the fourth finger of the left hand in a temperature-controlled environment to assess microvascular function in triathletes in response to consuming $300 \mathrm{ml} \cdot \mathrm{day}^{-1}$ of organic grape juice ( $1600 \mathrm{mg}$ polyphenols) for 20 days. Functional capillary density (capillaries with red cell flux), red blood cell velocity and time to peak velocity after $1 \mathrm{~min}$ arterial occlusion were all improved after grape juice supplementation, supporting the likelihood of better tissue perfusion after polyphenol supplementation, although this clearly needs to be directly tested in muscle. The ergogenic effects of blackcurrant supplementation are also proposed to be dependent on vascular mechanisms, but until recently there has been limited empirical data to support this assertion. Cook et al. [85] found that 7 days of supplementation with $600 \mathrm{mg}$ 
of blackcurrant powder (twice the daily dose provided in the exercise performance studies $[75-77,79]$ ) resulted in increased femoral artery diameter during a sustained submaximal maximum voluntary contraction (MVC) of the knee extensors (30\% MVC for $120 \mathrm{~s}$ ). These effects were accompanied by lower systolic and diastolic blood pressure and lower total peripheral resistance estimated via beat-beat finger blood pressure analysis.

The most plausible mechanisms for these apparent vascular effects are either reduced generation of ROS or improved capacity to detoxify ROS via antioxidant systems. Such reduced exposure to ROS will improve bioavailability of the potent vasodilator $\mathrm{NO}$, due to reduced production of peroxynitrite via the reaction of superoxide and NO. In vivo and in vitro evidence demonstrate that phenolic metabolites reduce NADPH oxidase activity, one of the key sources of superoxide production during exercise [47]. This is corroborated by the evidence that acute polyphenol supplementation protects against endurance exercise-induced oxidative damage. Consumption of a black grape, raspberry and redcurrant polyphenol blend ( $2000 \mathrm{mg}$ polyphenols, including $1212 \mathrm{mg}$ anthocyanins) during 90 min of cycling at $70 \% \dot{\mathrm{VO}}_{2} \max$ attenuated the exercise-induced elevation in plasma thiobarbituric acid-reacting substances (TBARS) and protein carbonyls in trained male cyclists [86]. Recreationally active participants experienced a reduced $\mathrm{F} 2$-isoprostane response to $2.5 \mathrm{~h}$ cycling at $60 \% \mathrm{~V}_{2}$ max when completed $2 \mathrm{~h}$ after consuming $100 \mathrm{~g}$ of dark chocolate $(\sim 250 \mathrm{mg}$ polyphenols [12]). Lyall et al. [87] found that the increase in plasma protein carbonyls after 30 min rowing at $80 \% \mathrm{~V}_{2}$ max was attenuated when blackcurrant powder $(120 \mathrm{mg}$ anthocyanins) was consumed immediately prior to exercise by recreationally active participants. However, none of these studies included an assessment of exercise performance.

In addition, there is evidence that chronic polyphenol consumption increases endogenous antioxidant system capacity via signalling through Nrf2 and antioxidant response element pathways (see Sect. 2) in a similar fashion to exercise adaptation [88]. Chronic polyphenol supplementation lowers exercise-induced oxidative stress, for instance $250 \mathrm{~g}$ blueberries consumed every day for 6 weeks with $375 \mathrm{~g}$ consumed $2 \mathrm{~h}$ prior to a $2.5 \mathrm{~h}$ run at $72 \% \dot{\mathrm{VO}}_{2}$ max attenuated the exercise-induced increase in plasma $\mathrm{F} 2$-isoprostanes and urinary oxidation products of RNA [89]. Young men consuming a diet supplemented with anthocyanin-rich purple sweet potato leaves versus a low polyphenol diet for 7 days experienced reduced plasma protein carbonyls and TBARS at rest and after $1 \mathrm{~h}$ exercise at $70 \% \mathrm{~V}_{2} \max$ [90]. Fuster-Munoz et al. [91] found that plasma malondialdehyde (MDA) and PC were reduced in endurance athletes undergoing normal training when consuming $200 \mathrm{ml} \cdot \mathrm{day}^{-1}$ of pomegranate juice for 21 days. The ergogenic effects of polyphenols therefore seem to be underpinned by vascular and antioxidant mechanisms. However, there is clearly a need for well-designed studies that measure exercise performance alongside robust measures of oxidative damage, antioxidant enzyme content and activity, inflammatory processes, macro- and micro-vascular function, and plasma phenolics to confirm these ergogenic effects and the mediators of these effects.

\section{Fruit-derived Polyphenols and Recovery after Intensive Exercise}

\subsection{Rationale}

Exercise-induced muscle damage involves both mechanical and biochemical processes. Muscle fibres are exposed to high mechanical forces especially during explosive and/ or eccentric contractions, which can result in disruption to the extracellular matrix, contractile proteins, sarcoplasmic reticulum, t-tubules and sarcolemma. There is subsequent disruption of calcium homeostasis with elevated resting calcium concentration [92], which may then contribute to further damage through activation of calcium sensitive proteases such as calpain resulting in increased proteolysis of susceptible proteins such as desmin and actin, thus worsening the ultrastructural damage [92]. In addition, there is increased generation of reactive oxygen species in an exercise intensity- and mode-dependent fashion [51, 93], which will cause oxidative modification of proteins and other molecules resulting in altered function and damage. Such processes will be particularly important contributing factors to the initial damage induced by high-intensity prolonged activities that do not involve eccentric muscle actions.

This initial damage, whether mechanical or biochemical, triggers a potent inflammatory response with damaged fibres releasing pro-inflammatory cytokines, which serve as chemo-attractants for neutrophils and macrophages and activate ROS generating enzymes within the muscle [94]. Neutrophil infiltration and activation occurs within $2 \mathrm{~h}$ of damage, generally peaking within 6-24 $\mathrm{h}$ and then rapidly decreasing [95]. Neutrophils are rich in enzymes such as NADPH oxidase, and release ROS and proteolytic enzymes that may exacerbate the initial muscle damage [96], but also facilitate regeneration by removal of debris and activation of satellite cells [97]. Shortly after neutrophil infiltration, macrophages derived from blood monocytes accumulate within the damaged tissue. Their role is to scavenge debris and apoptotic cells and in addition release a range of growth factors and other substances that trigger remodelling of extracellular matrix, contractile and vascular elements. Two macrophage populations have been identified: M1 and M2. M1 macrophages are pro-inflammatory and infiltrate muscle in the early stages of damage, and have been 
linked to proliferation of satellite cells [98]. It has been suggested that phagocytosis of damaged myogenic cells by M1 macrophages triggers their conversion to M2 macrophages [99]. These M2 macrophages release anti-inflammatory cytokines (transforming growth factor- $\beta$ and interleukin 10) and release growth factors such as insulin-like growth factor 1 to support regeneration of the damaged tissue [100].

The central involvement of ROS generation and inflammation within the muscle damage and healing process suggests that polyphenol supplementation will influence these processes and therefore the rate of recovery. Polyphenols have been shown to inhibit activity of key ROS-generating enzymes such as NADPH oxidase, serve as radical scavengers, and with chronic supplementation also enhance endogenous antioxidant capacity. In addition, polyphenols have been shown to inhibit cyclo-oxygenase activity and suppress inflammation [101-103].

\subsection{Evidence of Enhanced Functional Recovery}

There is now a growing body of evidence that suggests that fruit-derived polyphenol supplementation enhances restoration of muscle function and reduces soreness after intensive exercise (Table 4). The effects of Montmorency cherry supplementation on recovery of muscle function or exercise performance after intensive exercise have been investigated in nine published studies thus far, of which five studies found favourable effects [104-108]. These studies involved recreationally active men [104], recreational runners [105] or trained athletes [106-108], so unlike the acute performance effects of polyphenol supplementation, it seems that beneficial effects on recovery are accessible to both trained and less well-trained individuals. Nor does the efficacy of the supplement seem to be influenced by the mode of exercise used to induce muscle damage, since different approaches or muscle groups were damaged in each of these studies (intensive knee extensor resistance exercise [106]; eccentric elbow flexor exercise [104]; marathon running [105]; high-intensity stochastic cycling [108] or $90 \mathrm{~min}$ repeated high-intensity shuttle running [107]). In these studies, Montmorency cherry was provided in the form of a juice drink, which was consumed morning and evening for at least 3 days prior to exercise, and provided at least $1200 \mathrm{mg}$ polyphenols per day. Conversely, in studies where recovery of muscle function or exercise performance was not enhanced [109-111, 120], either a lower (and presumably insufficient) dose of Montmorency cherry was provided in powder form (480 mg Montmorency cherry powder in a single dose [109]; $733 \mathrm{mg}$ polyphenols split into two doses [110]) or the intensive exercise task did not induce a measurable decline in muscle strength [110] or exercise performance [111], thus by definition making it impossible to improve recovery. As well as differences in dose and frequency of supplementation, it is possible that differences in post-harvest processing of cherries between juice and powder production may induce variation in the polyphenol blend, and thus contribute to the discrepancy in findings across studies utilising Montmorency cherry powder $[109,110]$ versus juice [104-108, 111, 112]. In summary, consumption of Montmorency cherry juice or concentrate providing $600 \mathrm{mg}$ polyphenols morning and evening for at least 3 days prior to exercise and during recovery has consistently been shown to improve recovery of muscle function. Further studies are required to identify the optimal dose, frequency and duration of consumption.

The effect of Montmorency cherry supplementation on muscle soreness after intensive exercise has been assessed in eight studies, and soreness measured using a visual analogue pain scale [104, 107, 112] or pressure pain tolerance [109] was reduced in half of these studies. There is no clear pattern to explain this variation across studies: in two studies favourable effects on both recovery of muscle strength and soreness were evident $[104,107]$; in others favourable effects on muscle function but not soreness were observed [105, 106]; and Beals et al. [110] and McCormick et al. [111] found no effects on either soreness or muscle function, but the exercise protocol did not induce loss of muscle strength or soreness. Lastly, Kuehl et al. [112] found significant reductions in muscle soreness in runners who consumed Montmorency cherry juice (1200 mg polyphenols) for 7 days prior to and on the day of the Hood to Coast relay race, but changes in muscle function were not assessed. Suppression of inflammation induced by muscle damage is the proposed mechanism by which polyphenol supplementation may attenuate muscle soreness [113]. At present measures of serum markers of inflammation are available for some but not all studies, and there seems to be no relationship between reduced soreness after Montmorency cherry supplementation and serum markers of inflammation. Levers et al. [109] found reduced soreness but no effect on serum TNF $\alpha$, IL1 $\beta$, IL6 or IL8; Kuehl et al. [112] and Connolly et al. [104] found reductions in soreness but no serum inflammatory marker data are available. Howatson et al. [105] found reduced serum IL6 and C-reactive protein (CRP) after cherry supplementation but no significant effect on soreness; only Bell et al. [107] found reductions in both soreness and serum IL6 response, but serum TNF $\alpha$, IL1 $\beta$, IL8 and CRP were not affected by Montmorency cherry supplementation. Several studies found no effects of Montmorency cherry supplementation on serum markers of inflammation [106, 110,111], but these involved unilateral and/or relatively small muscle group exercise, which did not result in elevations in systemic markers of inflammation. Therefore, the absence of polyphenol effects in these studies is unsurprising. By definition, soreness is a highly subjective measure even when pressure pain tolerance is measured using an algometer, hence although important for athlete performance it is difficult to reliably 







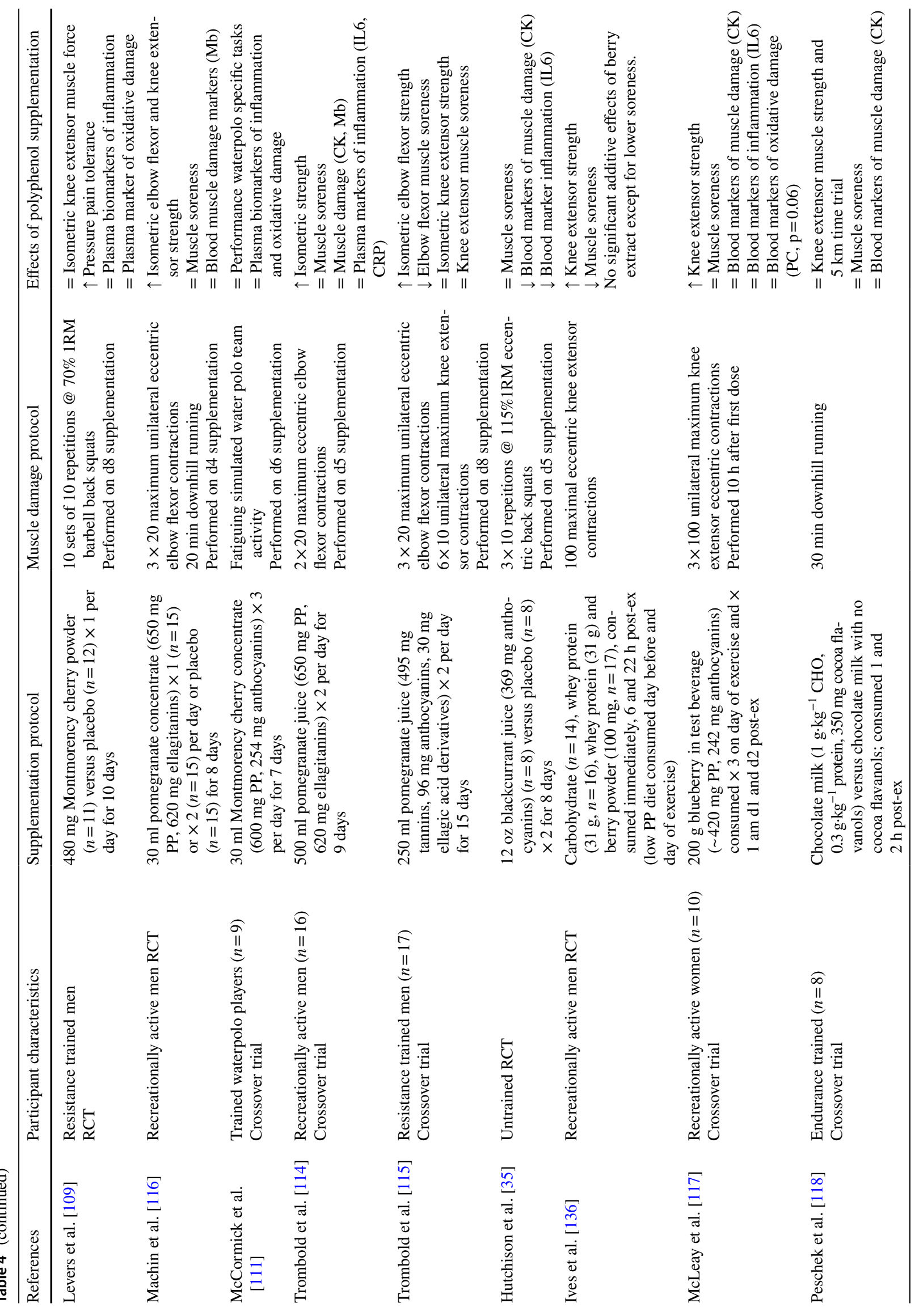


and objectively quantify. The quantification of inflammation within the damaged muscle itself, alongside measures of muscle soreness, could be an important step forward in understanding the effects of polyphenols.

Pomegranate juice consumption has also been shown to enhance recovery of elbow flexor [114-116], and knee extensor [116] muscle function after intensive exercise in recreationally active men. However, Trombold et al. [115] found that in resistance-trained men, pomegranate juice (250 $\mathrm{ml}$ providing $~ 620 \mathrm{mg}$ polyphenols) consumption twice per day for 7 days prior to and after exercise resulted in faster recovery of elbow flexor but not knee extensor isometric strength compared to placebo, after muscle damage was induced by eccentric elbow flexor and knee extensor exercise. The knee extensors were relatively refractory to muscle damage (15-20\% reduction in isometric strength vs. $25-35 \%$ loss of elbow flexor isometric strength) in this population, which may contribute to the lack of polyphenol effects in knee extensors in this population. In contrast, Machin et al. [116] found that recovery of both elbow flexor and knee extensor strength in recreationally active men was enhanced by consumption of pomegranate concentrate providing $650 \mathrm{mg}$ polyphenols either once or twice per day for 3 days prior to exercise, suggesting that the lower polyphenol dose was equally effective.

Only Trombold et al. [115] found that pomegranate supplementation reduced muscle soreness, specifically after eccentric elbow flexor exercise in resistance-trained men, but no serum markers of inflammation were measured in this study. Trombold et al. [114] and Machin et al. [116] measured muscle damage markers myoglobin $(\mathrm{Mb})$ and/or creatine kinase $(\mathrm{CK})$ and found that the exercise-induced increases were not affected by pomegranate supplementation. Serum markers of inflammation were measured in only one study [114], and there were no effects of pomegranate supplementation. However, as observed for Montmorency cherry supplementation studies, damage to a relatively small muscle group (elbow flexors) was not sufficient to induce any change in serum IL6 or CRP, hence it is unsurprising that polyphenol effects were not detectable.

Blueberry supplementation consumed in the form of a smoothie on the day of exercise (1360 mg polyphenols) and during 2 days of recovery ( $420 \mathrm{mg}$ polyphenols per day) enhanced recovery of knee extensor strength after unilateral eccentric exercise in recreationally active women, but did not reduce muscle soreness or serum IL6 although there was a strong tendency for reduced oxidative modification of serum proteins (protein carbonyls) [117]. Conversely, Peschek et al. [118] found no effect of the addition of cocoa flavanols to chocolate milk in the recovery of muscle strength or $5-\mathrm{km}$ time trial performance or muscle soreness in eight endurance-trained males, when consumed 1 and $2 \mathrm{~h}$ after downhill running. However, this finding in this randomised crossover 
trial is confounded by the use of downhill running to induce muscle damage, with all second trials likely to be affected by repeated bout effect, irrespective of treatment [119]. With the exception of McCormick et al. [111], all other studies reported here either adopted unilateral exercise for crossover trials to minimise repeated bout effects or utilised parallel group design to avoid repeated bout effects, although such studies are susceptible to the high degree of inter-individual variation evident in muscle damage and soreness responses.

\subsection{Mechanisms of Action}

Serum markers of oxidative damage (TBARS, MDA, lipid hydroperoxides, F2-isoprostanes, protein carbonyls, nitrotyrosine) were measured in five of the nine studies that found favourable effects of polyphenol supplementation on recovery of muscle function. Oxidative damage was suppressed either significantly (TBARS [105]; protein carbonyls [106]) or there was a strong non-statistically significant trend (lipid hydroperoxides [107]; protein carbonyls [117]) or in only one study there was no effect (lipid hydroperoxides [108]). A number of other studies have found reductions in oxidative damage markers after intensive exercise with prior polyphenol supplementation, although changes in muscle function were not measured (Montmorency cherry, $1300 \mathrm{mg} \cdot \mathrm{day}^{-1}$ polyphenols [120]; blackcurrant, $240 \mathrm{mg}$ anthocyanin [87]; pomegranate juice, $2560 \mathrm{mg} \cdot$ day $^{-1}$ polyphenols [121]). As described earlier (Sect. 2.1), it seems unlikely that polyphenols serve as direct antioxidants due to their relatively low concentration relative to endogenous antioxidants in serum and tissue. It is more likely that chronic supplementation ( $>3$ days) reduces serum markers of oxidative damage via upregulation of endogenous antioxidants through Nrf2 and antioxidant response element pathway signalling $[24,122]$. Tart cherry juice consumption has been shown to increase hepatic superoxide dismutase and glutathione peroxidase activity in mice [123]. Supplementation with anthocyanins isolated from purple sweet potato increased Nrf2 gene expression and Nrf2 nuclear translocation in rat liver [124]. Charles et al. [125] recently demonstrated that the age-related increases in oxidative stress and declines in mitochondrial function in mice were prevented by supplementation with an anthocyanin-rich extract derived from red grapes. This was achieved both via reduced reactive oxygen species generation as well as increased endogenous antioxidant enzyme gene expression. Dark chocolate supplementation for 3 months has also been shown to enhance superoxide dismutase and catalase expression in muscle of patients with heart failure and type 2 diabetes [48], and more recently has been shown to reduce carbonylation of proteins within skeletal muscle of healthy adults [126]. In contrast, McLeay et al. [117] only commenced blueberry supplementation $10 \mathrm{~h}$ prior to intensive exercise and hence increased endogenous antioxidant capacity is an unlikely explanation of the enhanced restoration of muscle function and a strong trend for lower serum protein carbonylation. Blueberry supplementation has been shown to suppress neutrophil NADPH oxidase activity [14], one of the key sources of superoxide production, which may contribute to the observed effects. A range of polyphenols have been shown to inhibit superoxide producing enzymes, such as NADPH oxidase and xanthine oxidase (for review, see Maraldi [47]).

Polyphenols have been shown to inhibit cyclo-oxygenase activity (COX1 and COX2) in similar fashion to non-steroidal anti-inflammatory drugs, and there is extensive in vitro and in vivo evidence of anti-inflammatory effects of polyphenols (for review see Peluso et al. [127]). The important and complex contribution of inflammatory pathways to the healing and remodelling process suggests the anti-inflammatory effects of polyphenols may be a key component of the mechanisms of action. Ten of the reviewed studies included serum markers of inflammation, with polyphenol-induced reductions in serum IL6 response to intensive exercise in five studies $[34,105,107,108,120])$. However, muscle soreness was attenuated in only one of these studies [107], whilst recovery of muscle function was enhanced in both studies where isometric force and inflammatory marker data were available [105, 107]. In four studies [106, 110, 111, 114], there was no effect of polyphenol supplementation on serum markers of inflammation; however, the exercise protocol employed did not induce elevation in any serum markers in these studies. In the remaining studies, polyphenol supplementation did not affect serum markers of inflammation despite enhanced recovery of muscle function [117] and reduced soreness [109]. The reliance on proxy serum markers of inflammation does not provide sufficient sensitivity to understand processes taking place within the damaged muscle itself. This point was clearly confirmed by Jajtner [128], since supplementation with a proprietary blend of green and black tea polyphenols suppressed IL8 protein expression in human skeletal muscle after intensive exercise, but there was no effect on circulating IL8 concentration. Myburgh et al. [129] investigated the effect of grape seed-derived proanthocyanidolic oligomer (PCO) supplementation on the healing process after hindlimb contusion injury in male Wistar rats. PCO treated rats exhibited reduced neutrophil activation on day 1 , normal magnitude but earlier macrophage response and earlier satellite cell activation. However, equivalent data from studies with human participants are not yet available.

Sleep is an important component of an athlete's programme to ensure optimal recovery. However, use of stimulant supplements, evening training sessions and matches, travel and other aspects of an athlete's busy life can compromise both sleep quantity and quality. There is some evidence to suggest that Montmorency cherry [130, 131] and Jerte valley $[132,133]$ cherry supplementation improves sleep 
quality (assessed via accelerometry and sleep questionnaire), which may also contribute to the observed benefits for recovery. Modulation of the pro-inflammatory cytokine response to exercise has been suggested as one possible mechanism by which sleep quality may be improved, as well as the melatonin content of cherries. Elevation of urinary melatonin metabolites after 7 days' cherry supplementation in parallel with enhanced sleep quality supports this assertion. However, in these studies supplements were consumed in the morning and evening whereas melatonin supplements are normally prescribed to be consumed prior to sleep, and in addition the dose provided by cherries is relatively low ( $85 \mu \mathrm{g}$ vs. $2-3 \mathrm{mg}$ clinical dose) and there is some scepticism surrounding this proposition [134]. Nevertheless, recent data from in vivo rat studies suggest that co-ingestion of melatonin with caffeic acid and/or quercetin enhances melatonin pharmacokinetics [135]. More human in vivo studies are needed to verify the somniferous effects of Montmorency cherry and other polyphenols and improve understanding of the mechanism.

\section{Methodological Limitations and Future Work}

The existing literature is flawed by a number of limitations that preclude the identification of optimal polyphenol dosing strategies for desired outcomes and also constrain understanding of the mechanisms of action. A key challenge in utilising natural fruit-derived supplements is that the polyphenol blend is influenced by the plant species, growing conditions and post-harvest processing. As a consequence, the polyphenol content of supplements will vary from batch to batch, but relatively few of the published studies provide detailed composition of the batch specific polyphenol blend consumed. This is essential for future work to ensure the accuracy of dose response data and hence our ability to identify optimal polyphenol doses and blends.

Dietary controls are a further factor worthy of consideration. Several of the reviewed studies incorporated some element of dietary polyphenol restriction $[11,64,67,80,82$, $107,120,136]$, in attempts to reduce the background noise that may be introduced by variation in dietary polyphenol intake, but which may also maximise the effects produced by polyphenol supplementation. Habitual polyphenol intake is difficult to accurately quantify, since despite our knowledge that polyphenol content of foods will be highly variable, reliance on standard values is required (http://phenol-explo rer.eu/ is an excellent resource for this purpose). Accuracy is also influenced by the known proclivity for under- and over-reporting of food intake using diet diaries. Population estimates of average intakes are diverse depending upon the plant content of diets, with total polyphenols ranging from
380 to $1400 \mathrm{mg}$ [137], anthocyanins $\sim 60 \mathrm{mg} \cdot \mathrm{day}^{-1}$, flavonols 20-35 mg $\cdot$ day $^{-1}$, catechins $18-50 \mathrm{mg} \cdot$ day $^{-1}$, hydroxycinnamic acids $800 \mathrm{mg} \cdot \mathrm{day}^{-1}$ (coffee drinkers) (for a review, see Manach et al. [138]) and proanthocyanidins $\sim 95 \mathrm{mg} \cdot \mathrm{day}^{-1}$ [139]. Many of the studies reviewed here provide $>1 \mathrm{~g}$ of polyphenols per day containing high levels of anthocyanins (cherry, blueberry, blackcurrant $200-550 \mathrm{mg}$ ) or ellagitannins (pomegranate $600 \mathrm{mg}$ ), which is many-fold higher than habitual intake. For this reason and to ensure the ecological validity of the data, it would seem that superimposing polyphenol supplementation onto the backdrop of habitual diet is the most appropriate approach.

Polyphenol chemistry is highly complex, but to date, studies in which the recovery and performance effects of polyphenol supplementation have been assessed have not included quantification of the plasma phenolics. Such measurements may allow identification of the bioactive metabolites and inform optimisation of the polyphenol blends consumed.

Our understanding of the mechanisms by which polyphenols exert favourable effects on performance and recovery is limited by the dearth of data on processes occurring within muscle. Published studies have relied upon proxy markers within serum to inform understanding of the antioxidant and anti-inflammatory processes that seem likely to underpin the beneficial effects observed. As described recently by Close et al. [140], many of the serum markers of oxidative damage are flawed and over-simplify the complexity of redox regulation. Certainly, blood markers are a poor surrogate for direct analysis of muscle tissue. To further progress understanding, studies incorporating muscle biopsies are needed that allow direct assessment of signalling via Nrf2 and ARE pathways and changes in antioxidant enzyme activity in muscle after polyphenol supplementation.

The controversy with regard to antioxidant vitamin supplementation and training adaptation continues, with evidence of no effect [141] or attenuation of adaptation [142]. It is clear that ROS and inflammatory pathways are implicated in the cell-signalling pathways that drive training adaptation, so it is plausible that if these signals are suppressed by antioxidant supplementation, ergolytic effects will result. However, in contrast to antioxidant vitamins and minerals, the antioxidant effects of polyphenols do not seem to arise from radical scavenging but rather from up-regulation of endogenous antioxidant systems. Different effects might therefore be anticipated between vitamins and polyphenols; however, there is a lack of empirical data. Taub et al. [126] recently confirmed previous exercise mimetic observations in mice [143], by which supplementation with $20 \mathrm{~g}$ of epicatechinrich cocoa for 3 months resulted in increased $\dot{\mathrm{VO}}_{2} \max$ and significant increases in skeletal muscle 5' adenosine monophosphate-activated protein kinase (AMPK), PGC1 $\alpha$ and citrate synthase protein levels. A small number of 
training studies with human participants have been performed with isolated resveratrol supplementation with largely detrimental consequences either for performance [144-147] or cellular level [145, 147] adaptation. However, no studies have yet been published in which the effects of a fruit-derived blend of polyphenols on training adaptation have been investigated.

\section{Practical Application}

From a practical perspective, this review provides data to allow sport nutrition and sport science practitioners to make recommendations to coaches and athletes regarding the efficacy of polyphenols to improve performance and aid recovery from their chosen sport or training discipline. The results from several studies suggest that acute and chronic polyphenol supplementation is associated with an improvement of performance with no reported adverse side effects. Additionally, it appears that supplementation with fruit-derived polyphenols will assist in the recovery of muscle function and reduce muscle soreness following intensive exercise.

In particular, athletes participating in sports that involve time trials (cycling) and repeated sprints (field and court sports) may experience performance gains when ingesting an acute dose of polyphenols (1-2 $\mathrm{h}$ prior to competition) or supplementing polyphenols chronically (1-6 weeks prior to competition). Similarly, athletes participating in training sessions that involve the completion of repeated sprints (6-30 s) and repeated high-intensity interval training bouts may consider supplementing with polyphenols as improvements during training may translate to sporting performance although this remains to be experimentally demonstrated. Since performance effects were of similar magnitude for acute and chronic supplementation, current evidence would suggest that acute supplementation with $300 \mathrm{mg}$ polyphenols $1-2 \mathrm{~h}$ prior to exercise may be ergogenic. Whilst research supports the use of polyphenols in conjunction with high-intensity training, there is currently a lack of evidence to support its use in conjunction with resistance training.

As athletes' training and competition schedules increase, the optimisation of recovery post-exercise is imperative. The compounding effects of successive training sessions and/or competitive bouts on physiological and physical function may be attenuated with the use of polyphenols. Current evidence would suggest that supplementation with $>1000 \mathrm{mg}$ polyphenols per day for 3 or more days prior to and following exercise will enhance recovery following sporting events that induce muscle damage, such as heavy resistance training, and for tournament sports that involve successive matches or rounds with short recovery periods. Consumption of $450 \mathrm{~g}$ blueberries, $120 \mathrm{~g}$ blackcurrants or $300 \mathrm{~g}$ Montmorency cherries would approximately provide this dose
[3]. Practitioners should consider their athletes' personal taste preferences and lifestyle demands when recommending individual supplementation protocols to ensure compliance.

\section{Conclusions}

In summary, there is growing evidence that acute and chronic supplementation with fruit-derived polyphenols may enhance exercise performance, with the mechanisms most likely to be related to antioxidant and vascular effects. However, this research is at an early stage and more work is required to optimise dosing strategies and to determine the specific modes, intensities and durations of exercise for which ergogenic effects may be achieved. There is a larger body of evidence that suggests that chronic polyphenol consumption enhances recovery from intensive exercise. More research is still required to identify the optimal dose and blend of polyphenols to support recovery, and ideally future studies will measure processes within muscle as well as plasma phenolic concentrations so that the specific bioactive compounds and the mechanisms of action can be identified.

Acknowledgements This paper is part of a supplement supported by the Gatorade Sports Science Institute (GSSI). The supplement was guest edited by Lawrence L. Spriet, who attended a meeting of the GSSI Expert Panel in October 2017 and received honoraria from the GSSI, a division of PepsiCo, Inc., for his participation in the meeting. He received no honoraria for guest editing the supplement. Dr. Spriet suggested peer reviewers for each paper, which were sent to the Sports Medicine Editor-in-Chief for approval prior to being approached. Dr Spriet provided comments on each paper and made an editorial decision based on comments from the peer reviewers and the Editor-inChief. Where decisions were uncertain, Dr Spriet consulted with the Editor-in-Chief.

\section{Compliance with Ethical Standards}

Funding Joanna Bowtell received an honorarium from the GSSI for the writing of this manuscript. Vincent Kelly received no funding for the writing of this manuscript.

Conflicts of interest Joanna Bowtell and Vincent Kelly declare that they have no conflicts of interest relevant to the content of this review.

Open Access This article is distributed under the terms of the Creative Commons Attribution 4.0 International License (http://creativeco mmons.org/licenses/by/4.0/), which permits unrestricted use, distribution, and reproduction in any medium, provided you give appropriate credit to the original author(s) and the source, provide a link to the Creative Commons license, and indicate if changes were made. 


\section{References}

1. Duthie GG, Gardner PT, Kyle JAM. Plant polyphenols: are they the new magic bullet? Proc Nutr Soc. 2003;62(3):599-603.

2. Oracz J, Zyzelewicz D, Nebesny E. The content of polyphenolic compounds in cocoa beans (Theobroma cacao L.), depending on variety, growing region, and processing operations: a review. Crit Rev Food Sci Nutr. 2015;55(9):1176-92.

3. Rothwell JA, Medina-Remon A, Perez-Jimenez J, Neveu V, Knaze V, Slimani N, et al. Effects of food processing on polyphenol contents: a systematic analysis using Phenol-Explorer data. Mol Nutr Food Res. 2015;59(1):160-70.

4. Niether W, Smit I, Armengot L, Schneider M, Gerold G, Pawelzik E. Environmental growing conditions in five production systems induce stress response and affect chemical composition of cocoa (Theobroma cacao L.) Beans. J Agric Food Chem. 2017;65(47):10165-73.

5. Hidalgo M, Sanchez-Moreno C, de Pascual-Teresa S. Flavonoidflavonoid interaction and its effect on their antioxidant activity. Food Chem. 2010;121(3):691-6.

6. Day AJ, Canada FJ, Diaz JC, Kroon PA, McLauchlan R, Faulds $\mathrm{CB}$, et al. Dietary flavonoid and isoflavone glycosides are hydrolysed by the lactase site of lactase phlorizin hydrolase. FEBS Lett. 2000;468(2-3):166-70.

7. Gee JM, DuPont MS, Day AJ, Plumb GW, Williamson G, Johnson IT. Intestinal transport of quercetin glycosides in rats involves both deglycosylation and interaction with the hexose transport pathway. J Nutr. 2000;130(11):2765-71.

8. Crozier A, Del Rio D, Clifford MN. Bioavailability of dietary flavonoids and phenolic compounds. Mol Aspects Med. 2010;31(6):446-67.

9. de Ferrars RM, Czank C, Zhang Q, Botting NP, Kroon PA, Cassidy A, et al. The pharmacokinetics of anthocyanins and their metabolites in humans. Br J Pharmacol. 2014;171(13):3268-82.

10. Kay CD, Pereira-Caro G, Ludwig IA, Clifford MN, Crozier A. Anthocyanins and flavanones are more bioavailable than previously perceived: A review of recent evidence. In: Doyle MP, Klaenhammer TR, editors. Annual Review of Food Science and Technology, Vol 8. Palo Alto, USA: Annual Review Inc; 2017. p. $155-80$.

11. Decroix L, Tonoli C, Soares DD, Descat A, Drittij-Reijnders MJ, Weseler AR, et al. Acute cocoa flavanols intake has minimal effects on exercise-induced oxidative stress and nitric oxide production in healthy cyclists: a randomized controlled trial. J Int Soc Sports Nutr. 2017;14:28.

12. Davison G, Callister R, Williamson G, Cooper KA, Gleeson M. The effect of acute pre-exercise dark chocolate consumption on plasma antioxidant status, oxidative stress and immunoendocrine responses to prolonged exercise. Eur J Nutr. 2012;51(1):69-79.

13. Keane KM, Bell PG, Lodge JK, Constantinou CL, Jenkinson SE, Bass R, et al. Phytochemical uptake following human consumption of Montmorency tart cherry (L. Prunus cerasus) and influence of phenolic acids on vascular smooth muscle cells in vitro. Eur J Nutr. 2016;55(4):1695-705.

14. Rodriguez-Mateos A, Rendeiro C, Bergillos-Meca T, Tabatabaee S, George TW, Heiss C, et al. Intake and time dependence of blueberry flavonoid-induced improvements in vascular function: a randomized, controlled, double-blind, crossover intervention study with mechanistic insights into biological activity. Am J Clin Nutr. 2013;98(5):1179-91.

15. Rechner AR, Kuhnle G, Hu HL, Roedig-Penman A, van den Braak MH, Moore KP, et al. The metabolism of dietary polyphenols and the relevance to circulating levels of conjugated metabolites. Free Radic Res. 2002;36(11):1229-41.
16. Seeram NP, Zhang Y, McKeever R, Henning SM, Lee RP, Suchard MA, et al. Pomegranate juice and extracts provide similar levels of plasma and urinary ellagitannin metabolites in human subjects. J Med Food. 2008;11(2):390-4.

17. Bors W, Michel C, Stettmaier K. Structure-activity relationships governing antioxidant capacities of plant polyphenols. In: Packer L, editor. Flavonoids and other polyphenols. Oxford, UK:Academic Press; 2001. Pp. 166-80.

18. Morel I, Lescoat G, Cillard P, Cillard J. Role of flavonoids and iron chelation in antioxidant action. Oxygen Radic Biol Syst Pt D. 1994;234:437-43.

19. Kroon PA, Clifford MN, Crozier A, Day AJ, Donovan JL, Manach C, et al. How should we assess the effects of exposure to dietary polyphenols in vitro? Am J Clin Nutr. 2004;80(1):15-21.

20. Clifford MN. Diet-derived Phenols in plasma and tissues and their implications for health. Planta Med. 2004;70(12):1103-14.

21. Sies H. Total antioxidant capacity: appraisal of a concept. J Nutr. 2007;137(6):1493-5.

22. Lotito SB, Frei B. The increase in human plasma antioxidant capacity after apple consumption is due to the metabolic effect of fructose on urate, not apple-derived antioxidant flavonoids. Free Radical Biol Med. 2004;37(2):251-8.

23. Itoh K, Chiba T, Takahashi S, Ishii T, Igarashi K, Katoh Y, et al. An Nrf2 small Maf heterodimer mediates the induction of phase II detoxifying enzyme genes through antioxidant response elements. Biochem Biophys Res Commun. 1997;236(2):313-22.

24. Huang Y, Li WJ, Su ZY, Kong ANT. The complexity of the Nrf2 pathway: beyond the antioxidant response. J Nutr Biochem. 2015;26(12):1401-13.

25. McMahon M, Itoh K, Yamamoto M, Hayes JD. Keap1-dependent proteasomal degradation of transcription factor $\mathrm{Nrf} 2$ contributes to the negative regulation of antioxidant response element-driven gene expression. J Biol Chem. 2003;278(24):21592-600.

26. McMahon M, Thomas N, Itoh K, Yamamoto M, Hayes JD. Dimerization of substrate adaptors can facilitate cullin-mediated ubiquitylation of proteins by a "Tethering" mechanism - A twosite interaction model for the Nrf2-Keap1 complex. J Biol Chem. 2006;281(34):24756-68.

27. Forman HJ, Davies KJA, Ursini F. How do nutritional antioxidants really work: nucleophilic tone and para-hormesis versus free radical scavenging in vivo. Free Radi Biol Med. 2014;66:24-35.

28. Moroney MA, Alcaraz MJ, Forder RA, Carey F, Hoult JRS. Selectivity of neutrophil 5-lipoxygenase and cyclo-oxygenase inhibition by an anti-inflammatory flavonoid glycoside and related aglycone flavonoids. J Pharm Pharmacol. 1988;40(11):787-92.

29. Noratto GD, Angel-Morales G, Talcott ST, Mertens-Talcott SU. Polyphenolics from acai (Euterpe oleracea Mart.) and red muscadine grape (Vitis rotundifolia) protect human umbilical vascular endothelial cells (HUVEC) from glucose- and lipopolysaccharide (LPS)-induced inflammation and target microRNA-126. J Agric Food Chem. 2011;59(14):7999-8012.

30. Esposito D, Chen A, Grace MH, Komarnytsky S, Lila MA. Inhibitory Effects of wild blueberry anthocyanins and other flavonoids on biomarkers of acute and chronic inflammation in vitro. J Agric Food Chem. 2014;62(29):7022-8.

31. Kelley DS, Rasooly R, Jacob RA, Kader AA, Mackey BE. Consumption of Bing sweet cherries lowers circulating concentrations of inflammation markers in healthy men and women. J Nutr. 2006;136(4):981-6.

32. Karlsen A, Paur I, Bohn SK, Sakhi AK, Borge GI, Serafini M, et al. Bilberry juice modulates plasma concentration of NF-kappa $B$ related inflammatory markers in subjects at increased risk of CVD. Eur J Nutr. 2010;49(6):345-55. 
33. Kolehmainen M, Mykkanen O, Kirjavainen PV, Leppanen T, Moilanen E, Adriaens M, et al. Bilberries reduce low-grade inflammation in individuals with features of metabolic syndrome. Mol Nutr Food Res. 2012;56(10):1501-10.

34. Hutchison AT, Flieller EB, Dillon KJ, Leverett BD. Blackcurrant nectar reduces muscle damage and inflammation following a bout of high-intensity eccentric contractions. J Diet Suppl. 2016;13:1-15.

35. Matthaiou CM, Goutzourelas N, Stagos D, Sarafoglou E, Jamurtas A, Koulocheri SD, et al. Pomegranate juice consumption increases GSH levels and reduces lipid and protein oxidation in human blood. Food Chem Toxicol. 2014;73:1-6.

36. Martin MA, Ramos S. Cocoa polyphenols in oxidative stress: potential health implications. J Funct Foods. 2016;27:570-88.

37. Hooper L, Kay C, Abdelhamid A, Kroon PA, Cohn JS, Rimm EB, et al. Effects of chocolate, cocoa, and flavan-3-ols on cardiovascular health: a systematic review and meta-analysis of randomized trials. Am J Clin Nutr. 2012;95(3):740-51.

38. Chou EJ, Keevil JG, Aeschlimann S, Wiebe DA, Folts JD, Stein $\mathrm{JH}$. Effect of ingestion of purple grape juice on endothelial function in patients with coronary heart disease. Am J Cardiol. 2001;88(5):553.

39. Coimbra SR, Lage SH, Brandizzi L, Yoshida V, da Luz PL. The action of red wine and purple grape juice on vascular reactivity is independent of plasma lipids in hypercholesterolemic patients. Braz J Med Biol Res. 2005;38(9):1339-47.

40. Chaves AA, Joshi MS, Coyle CM, Brady JE, Dech SJ, Schanbacher BL, et al. Vasoprotective endothelial effects of a standardized grape product in humans. Vascul Pharmacol. 2009;50(1-2):20-6.

41. Barona J, Aristizabal JC, Blesso CN, Volek JS, Fernandez ML. Grape polyphenols reduce blood pressure and increase flowmediated vasodilation in men with metabolic syndrome. J Nutr. 2012;142(9):1626-32.

42. Clifton PM. Effect of grape seed extract and quercetin on cardiovascular and endothelial parameters in high-risk subjects. J Biomed Biotechnol. 2004;1(5):272-8.

43. Poreba R, Skoczynska A, Gac P, Poreba M, Jedrychowska I, Affelska-Jercha A, et al. Drinking of chokeberry juice from the ecological farm Dzieciolowo and distensibility of brachial artery in men with mild hypercholesterolemia. Ann Agric Environ Med. 2009;16(2):305-8.

44. Khan F, Ray S, Craigie AM, Kennedy G, Hill A, Barton KL, et al. Lowering of oxidative stress improves endothelial function in healthy subjects with habitually low intake of fruit and vegetables: a randomized controlled trial of antioxidant- and polyphenol-rich blackcurrant juice. Free Radic Biol Med. 2014;72:232-7.

45. Kay CD, Hooper L, Kroon PA, Rimm EB, Cassidy A. Relative impact of flavonoid composition, dose and structure on vascular function: a systematic review of randomised controlled trials of flavonoid-rich food products. Mol Nutr Food Res. 2012;56(11):1605-16

46. Chalopin M, Tesse A, Martinez MC, Rognan D, Arnal J-F, Andriantsitohaina R. Estrogen receptor alpha as a key target of red wine polyphenols action on the endothelium. Plos One. 2010;5(1):e8554.

47. Maraldi T. Natural compounds as modulators of NADPH oxidases. Oxid Med Cell Longev. 2013. https://doi. org/10.1155/2013/271602.

48. Ramirez-Sanchez I, Taub PR, Ciaraldi TP, Nogueira L, Coe T, Perkins G, et al. (-)-Epicatechin rich cocoa mediated modulation of oxidative stress regulators in skeletal muscle of heart failure and type 2 diabetes patients. Int J Cardiol. 2013;168(4):3982-90.
49. Allen DG, Lamb GD, Westerblad H. Skeletal muscle fatigue: cellular mechanisms. Physiol Rev. 2008;88(1):287-332.

50. Reid MB. Redox interventions to increase exercise performance. J Physiol. 2016;594(18):5125-33.

51. Bailey DM, Davies B, Young IS, Jackson MJ, Davison GW, Isaacson R, et al. EPR spectroscopic detection of free radical outflow from an isolated muscle bed in exercising humans. J Appl Physiol. 2003;94(5):1714.

52. Bailey DM, Lawrenson L, McEneny J, Young IS, James PE, Jackson SK, et al. Electron paramagnetic spectroscopic evidence of exercise-induced free radical accumulation in human skeletal muscle. Free Radic Res. 2007;41(2):182-90.

53. Merry TL, McConell GK. Skeletal muscle glucose uptake during exercise: a focus on reactive oxygen species and nitric oxide signaling. IUBMB Life. 2009;61(5):479-84.

54. Trinity JD, Broxterman RM, Richardson RS. Regulation of exercise blood flow: role of free radicals. Free Radic Biol Med. 2016;98:90-102.

55. Durand MJ, Dharmashankar K, Bian JT, Das E, Vidovich M, Gutterman DD, et al. Acute exertion elicits a $\mathrm{H}_{2} \mathrm{O}_{2}$-dependent vasodilator mechanism in the microvasculature of exercisetrained but not sedentary adults. Hypertension. 2015;65(1):140.

56. Donato AJ, Uberoi A, Bailey DM, Wray D, Richardson RS. Exercise-induced brachial artery vasodilation: effects of antioxidants and exercise training in elderly men. Am J Physiol Heart Circ Physiol. 2010;298(2):H671-8.

57. Sun QA, Hess DT, Nogueira L, Yong S, Bowles DE, Eu J, et al. Oxygen-coupled redox regulation of the skeletal muscle ryanodine receptor- $\mathrm{Ca}^{2+}$ release channel by NADPH oxidase 4 . Proc Natl Acad Sci USA. 2011;108(38):16098-103.

58. Powers SK, Talbert EE, Adhihetty PJ. Reactive oxygen and nitrogen species as intracellular signals in skeletal muscle. J Physiol Lond. 2011;589(9):2129-38.

59. Gandevia SC. Spinal and supraspinal factors in human muscle fatigue. Physiol Rev. 2001;81(4):1725-89.

60. Cobley JN, McGlory C, Morton JP, Close GL. N-Acetylcysteine's attenuation of fatigue after repeated bouts of intermittent exercise: practical implications for tournament situations. Int J Sport Nutr Exerc Metab. 2011;21(6):451-61.

61. Corn SD, Barstow TJ. Effects of oral N-acetylcysteine on fatigue, critical power, and $\mathrm{W}$ 'in exercising humans. Respir Physiol Neurobiol. 2011;178(2):261-8.

62. McKenna MJ, Medved I, Goodman CA, Brown MJ, Bjorksten $\mathrm{AR}$, Murphy KT, et al. $\mathrm{N}$-acetylcysteine attenuates the decline in muscle $\mathrm{Na}+, \mathrm{K}+$-pump activity and delays fatigue during prolonged exercise in humans. J Physiol Lond. 2006;576(1):279-88.

63. Trexler ET, Smith-Ryan AE, Melvin MN, Roelofs EJ, Wingfield HL. Effects of pomegranate extract on blood flow and running time to exhaustion. Appl Physiol Nutr Metab Physiologie Appliquee Nutrition Et Metabolisme. 2014;39(9):1038-42.

64. Crum EM, Muhamed AMC, Barnes M, Stannard SR. The effect of acute pomegranate extract supplementation on oxygen uptake in highly-trained cyclists during high-intensity exercise in a high altitude environment. J Int Soc Sports Nutr. 2017;14:14.

65. Roelofs EJ, Smith-Ryan AE, Trexler ET, Hirsch K, Mock MG. Effects of pomegranate extract on blood flow and vessel diameter after high-intensity exercise in young, healthy adults. Eur J Sport Sci. 2017;17(3):317-25.

66. Cases J, Romain C, Marin-Pagan C, Chung LH, Rubio-Perez JM, Laurent C, et al. Supplementation with a polyphenol-rich extract, PerfLoad (R), improves physical performance during high-intensity exercise: a randomized, double blind, crossover trial. Nutrients. 2017;9(4):421.

67. Keane KM, Bailey SJ, Vanhatalo A, Jones AM, Howatson G. Effects of montmorency tart cherry (L-Prunus Cerasus) 
consumption on nitric oxide biomarkers and exercise performance. Scand J Med Sci Sports. 2018;28(7):1746-56.

68. Oh JK, Shin YO, Yoon JH, Kim SH, Shin HC, Hwang HJ. Effect of supplementation with Ecklonia cava polyphenol on endurance performance of college students. Int J Sport Nutr Exerc Metab. 2010;20(1):72-9.

69. Deley G, Guillemet D, Allaert FA, Babault N. An acute dose of specific grape and apple polyphenols improves endurance performance: a randomized, crossover, double-blind versus placebo controlled study. Nutrients. 2017;9(8):917.

70. Mazza G, Kay CD. Bioactivity, absorption, and metabolism of anthocyanins. Recent Adv Polyphenol Res. 2008;1:228-62.

71. Stalmach A, Edwards CA, Wightman JD, Crozier A. Identification of (poly)phenolic compounds in Concord grape juice and their metabolites in human plasma and urine after juice consumption. J Agric Food Chem. 2011;59(17):9512-22.

72. Holt RR, Lazarus SA, Sullards MC, Zhu QY, Schramm DD, Hammerstone JF, et al. Procyanidin dimer B2 epicatechin-(4 beta-8)-epicatechin in human plasma after the consumption of a flavanol-rich cocoa. Am J Clin Nutr. 2002;76(4):798-804.

73. Kang SW, Hahn S, Kim JK, Yang SM, Park BJ, Lee SC. Oligomerized lychee fruit extract (OLFE) and a mixture of vitamin $\mathrm{C}$ and vitamin $\mathrm{E}$ for endurance capacity in a double blind randomized controlled trial. J Clin Biochem Nutr. 2012;50(2):106-13.

74. Sadowska-Krepa E, Klapcinska B, Kimsa E. Effects of supplemetation with red grape skin polyphenolic extract and interval swimming test on the blood antioxidant status in healthy men. Medicina Sportiva. 2008;12(1):1-7.

75. Cook MD, Myers SD, Blacker SD, Willems MET. New Zealand blackcurrant extract improves cycling performance and fat oxidation in cyclists. Eur J Appl Physiol. 2015;115(11):2357-65.

76. Perkins IC, Vine SA, Blacker SD, Willems MET. New Zealand blackcurrant extract improves high-intensity intermittent running. Int J Sport Nutr Exerc Metab. 2015;25(5):487-93.

77. Willems MET, Cousins L, Williams D, Blacker SD. Beneficial effects of New Zealand blackcurrant extract on maximal sprint speed during the Loughborough intermittent shuttle test. Sports. 2016;4(3):42.

78. Godwin C, Cook MD, Willems MET. Effect of New Zealand blackcurrant extract on performance during the running based anaerobic sprint test in trained youth and recreationally active male football players. Sports. 2017;5(2):69.

79. Murphy CA, Cook MD, Willems MET. Effect of New Zealand blackcurrant extract on repeated cycling time trial performance. Sports. 2017;5(2).

80. Braakhuis AJ, Hopkins WG, Lowe TE. Effects of dietary antioxidants on training and performance in female runners. Eur $\mathrm{J}$ Sport Sci. 2014;14(2):160-8.

81. Trinity JD, Pahnke MD, Trombold JR, Coyle EF. Impact of polyphenol antioxidants on cycling performance and cardiovascular function. Nutrients. 2014;6(3):1273-92.

82. Allgrove J, Farrell E, Gleeson M, Williamson G, Cooper K. Regular dark chocolate consumption's reduction of oxidative stress and increase of free-fatty-acid mobilization in response to prolonged cycling. Int J Sport Nutr Exerc Metab. 2011;21(2):113-23.

83. Richards JC, Lonac MC, Johnson TK, Schweder MM, Bell C. Epigallocatechin-3-gallate increases maximal oxygen uptake in adult humans. Med Sci Sports Exerc. 2010;42(4):739-44.

84. Goncalves MC, Bezerra FF, de Araujo Eleutherio EC, Bouskela E, Koury J. Organic grape juice intake improves functional capillary density and postocclusive reactive hyperemia in triathletes. Clinics. 2011;66(9):1537-41.
85. Cook MD, Myers SD, Gault ML, Willems MET. Blackcurrant alters physiological responses and femoral artery diameter during sustained isometric contraction. Nutrients. 2017;9(6):556.

86. Morillas-Ruiz J, Villegas Garcia J, Lopez F, Vidal-Guevara M, Zafrilla P. Effects of polyphenolic antioxidants on exerciseinduced oxidative stress. Clin Nutr. 2006;25(3):444-53.

87. Lyall K, Hurst S, Cooney J, Jensen D, Lo K, Hurst R, et al. Short-term blackcurrant extract consumption modulates exercise-induced oxidative stress and lipopolysaccharide-stimulated inflammatory responses. Am J Physiol. 2009;297(1):R70-81.

88. Ji LL. Modulation of skeletal muscle antioxidant defense by exercise: role of redox signaling. Free Radic Biol Med. 2008;44(2):142-52.

89. Mcanulty LS, Nieman DC, Dumke CL, Shooter LA, Henson DA, Utter AC, et al. Effect of blueberry ingestion on natural killer cell counts, oxidative stress, and inflammation prior to and after $2.5 \mathrm{~h}$ of running. Appl Physiol Nutr Metab-Physiologie Appliquee Nutrition et Metabolisme. 2011;36(6):976-84.

90. Chang WH, Hu SP, Huang YF, Yeh TS, Liu JF. Effect of purple sweet potato leaves consumption on exercise-induced oxidative stress and IL-6 and HSP72 levels. J Appl Physiol. 2010;109(6):1710-5.

91. Fuster-Munoz E, Roche E, Funes L, Martinez-Peinado P, Sempere JM, Vicente-Salar N. Effects of pomegranate juice in circulating parameters, cytokines, and oxidative stress markers in endurance-based athletes: a randomized controlled trial. Nutrition. 2016;32(5):539-45.

92. Belcastro AN, Shewchuk LD, Raj DA. Exercise-induced muscle injury: a calpain hypothesis. Mol Cell Biochem. 1998;179(1-2):135-45.

93. Bailey DM, Williams C, Betts JA, Thompson D, Hurst TL. Oxidative stress, inflammation and recovery of muscle function after damaging exercise: effect of 6-week mixed antioxidant supplementation. Eur J Appl Physiol. 2011;111(6):925-36.

94. Michailidis Y, Karagounis LG, Terzis G, Jamurtas AZ, Spengos $\mathrm{K}$, Tsoukas D, et al. Thiol-based antioxidant supplementation alters human skeletal muscle signaling and attenuates its inflammatory response and recovery after intense eccentric exercise. Am J Clin Nutr. 2013;98(1):233-45.

95. Paulsen G, Crameri R, Benestad HB, Fjeld JG, Morkrid $\mathrm{L}$, Hallen $\mathrm{J}$, et al. Time course of leukocyte accumulation in human muscle after eccentric exercise. Med Sci Sports Exerc. 2010;42(1):75-85.

96. Zerria K, Jerbi E, Hammami S, Maaroufi A, Boubaker S, Xiong JP, et al. Recombinant integrin CD11b A-domain blocks polymorphonuclear cells recruitment and protects against skeletal muscle inflammatory injury in the rat. Immunology. 2006;119(4):431-40.

97. Teixeira CFP, Zamuner SR, Zuliani JP, Fernandes CM, CruzHofling MA, Fernandes I, et al. Neutrophils do not contribute to local tissue damage, but play a key role in skeletal muscle regeneration, in mice injected with Bothrops asper snake venom. Muscle Nerve. 2003;28(4):449-59.

98. Rigamonti E, Touvier T, Clementi E, Manfredi AA, Brunelli S, Rovere-Querini P. Requirement of inducible nitric oxide synthase for skeletal muscle regeneration after acute damage. J Immunol. 2013;190(4):1767-77.

99. Arnold L, Henry A, Poron F, Baba-Amer Y, van Rooijen N, Plonquet $\mathrm{A}$, et al. Inflammatory monocytes recruited after skeletal muscle injury switch into antiinflammatory macrophages to support myogenesis. J Exp Med. 2007;204(5):1057-69.

100. Saclier M, Yacoub-Youssef H, Mackey AL, Arnold L, Ardjoune $\mathrm{H}$, Magnan M, et al. Differentially activated macrophages orchestrate myogenic precursor cell fate during human skeletal muscle regeneration. Stem cells. 2013;31(2):384-96. 
101. Wang HB, Nair MG, Strasburg GM, Chang YC, Booren AM, Gray JI, et al. Antioxidant and antiinflammatory activities of anthocyanins and their aglycon, cyanidin, from tart cherries vol 62, pg 296, 1999). J Nat Prod. 1999;62(5):802.

102. Seeram NP, Momin RA, Nair MG, Bourquin LD. Cyclooxygenase inhibitory and antioxidant cyanidin glycosides in cherries and berries. Phytomedicine. 2001;8(5):362-9.

103. Seeram NP. Berry fruits: compositional elements, biochemical activities, and the impact of their intake on human health, performance, and disease. J Agric Chem. 2008;56(3):627-9.

104. Connolly DAJ, McHugh MP, Padilla-Zakour OI. Efficacy of a tart cherry juice blend in preventing the symptoms of muscle damage. Br J Sports Med. 2006;40(8):679-83.

105. Howatson G, McHugh M, Hill J, Brouner J, Jewell A, van Someren $\mathrm{K}$, et al. Influence of tart cherry juice on indices of recovery following marathon running. Scand J Med Sci Sports. 2010;20(6):843-52.

106. Bowtell JL, Sumners DP, Dyer A, Fox P, Mileva KN. Montmorency cherry juice reduces muscle damage caused by intensive strength exercise. Med Sci Sports Exerc. 2011;43(8):1544-51.

107. Bell PG, Stevenson E, Davison GW, Howatson G. The effects of montmorency tart cherry concentrate supplementation on recovery following prolonged, intermittent exercise. Nutrients. 2016;8(7):441.

108. Bell PG, Walshe IH, Davison GW, Stevenson EJ, Howatson G. Recovery facilitation with Montmorency cherries following highintensity, metabolically challenging exercise. Appl Physiol Nutr Metab. 2015;40(4):414-23.

109. Levers K, Dalton R, Galvan E, Goodenough C, O'Connor A, Simbo S, et al. Effects of powdered Montmorency tart cherry supplementation on an acute bout of intense lower body strength exercise in resistance trained males. J Int Soc Sports Nutr. 2015;16:12.

110. Beals K, Allison KF, Darnell M, Lovalekar M, Baker R, Nieman DC, et al. The effects of a tart cherry beverage on reducing exercise-induced muscle soreness. Isokinet Exerc Sci. 2017;25(1):53-63.

111. McCormick R, Peeling P, Binnie M, Dawson B, Sim M. Effect of tart cherry juice on recovery and next day performance in welltrained water polo players. J Int Soc Sports Nutr. 2016;13:41.

112. Kuehl KS, Perrier ET, Elliot DL, Chesnutt JC. Efficacy of tart cherry juice in reducing muscle pain during running: a randomized controlled trial. J Int Soc Sports Nutr. 2010;7:17.

113. Mizumura K, Taguchi T. Delayed onset muscle soreness: involvement of neurotrophic factors. J Physiol Sci. 2016;66(1):43-52.

114. Trombold JR, Barnes JN, Critchley L, Coyle EF. Ellagitannin consumption improves strength recovery 2-3 d after eccentric exercise. Med Sci Sports Exerc. 2010;42(3):493-8.

115. Trombold JR, Reinfeld AS, Casler JR, Coyle EF. The effect of pomegranate juice supplementation on strength and soreness after eccentric exercise. J Strength Cond Res. 2011;25(7):1782-8.

116. Machin DR, Christmas KM, Chou TH, Hill SC, Van Pelt D, Trombold JR, et al. Dose response effects of pomegranate juice concentrate supplementation on DOMS. Med Sci Sports Exerc. 2012;44:315.

117. McLeay Y, Barnes MJ, Mundel T, Hurst SM, Hurst RD, Stannard SR. Effect of New Zealand blueberry consumption on recovery from eccentric exercise-induced muscle damage. J Int Soc Sports Nutr. 2012;9:19.

118. Peschek K, Pritchett R, Bergman E, Pritchett K. The effects of acute post exercise consumption of two cocoa-based beverages with varying flavanol content on indices of muscle recovery following downhill treadmill running. Nutrients. 2014;6(1):50-62.

119. Hyldahl RD, Chen TC, Nosaka K. Mechanisms and mediators of the skeletal muscle repeated bout effect. Exerc Sport Sci Rev. 2017;45(1):24-33.
120. Bell PG, Walshe IH, Davison GW, Stevenson E, Howatson G. Montmorency cherries reduce the oxidative stress and inflammatory responses to repeated days high-intensity stochastic cycling. Nutrients. 2014;6(2):829-43.

121. Ammar A, Turki M, Hammouda O, Chtourou H, Trabelsi K, Bouaziz M, et al. Effects of pomegranate juice supplementation on oxidative stress biomarkers following weightlifting exercise. Nutrients. 2017;9(8):819.

122. Birringer M. Hormetics: dietary triggers of an adaptive stress response. Pharm Res. 2011;28(11):2680-94.

123. Saric A, Sobocanec S, Balog T, Kusic B, Sverko V, DragovicUzelac V, et al. Improved antioxidant and anti-inflammatory potential in mice consuming sour cherry juice (Prunus Cerasus cv. Maraska). Plant Foods Hum Nutr. 2009;64(4):231-7.

124. Hwang YP, Choi JH, Yun HJ, Han EH, Kim HG, Kim JY, et al. Anthocyanins from purple sweet potato attenuate dimethylnitrosamine-induced liver injury in rats by inducing Nrf2mediated antioxidant enzymes and reducing COX-2 and iNOS expression. Food Chem Toxicol. 2011;49(1):93-9.

125. Charles AL, Meyer A, Dal-Ros S, Auger C, Keller N, Ramamoorthy TG, et al. Polyphenols prevent ageing-related impairment in skeletal muscle mitochondrial function through decreased reactive oxygen species production. Exp Physiol. 2013;98(2):536-45.

126. Taub PR, Ramirez-Sanchez I, Patel M, Higginbotham E, Moreno-Ulloa A, Roman-Pintos LM, et al. Beneficial effects of dark chocolate on exercise capacity in sedentary subjects: underlying mechanisms. A double blind, randomized, placebo controlled trial. Food Funct. 2016;7(9):3686-93.

127. Peluso I, Raguzzini A, Serafini M. Effect of flavonoids on circulating levels of TNF- and IL-6 in humans: a systematic review and meta-analysis. Mol Nutr Food Res. 2013;57(5):784-801.

128. Jajtner AR, Hoffman JR, Townsend JR, Beyer KS, Varanoske AN, Church DD, et al. The effect of polyphenols on cytokine and granulocyte response to resistance exercise. Physiol Rep. 2016;4(124):e13058.

129. Myburgh KH, Kruger MJ, Smith C. Accelerated skeletal muscle recovery after in vivo polyphenol administration. J Nutr Biochem. 2012;23(9):1072-9.

130. Pigeon WR, Carr M, Gorman C, Perlis ML. Effects of a tart cherry juice beverage on the sleep of older adults with insomnia: a pilot study. J Med Food. 2010;13(3):579-83.

131. Howatson G, Bell PG, Tallent J, Middleton B, McHugh MP, Ellis J. Effect of tart cherry juice (Prunus cerasus) on melatonin levels and enhanced sleep quality. Eur J Nutr. 2012;51(8):909-16.

132. Garrido M, Gonzalez-Gomez D, Lozano M, Barriga C, Paredes $\mathrm{SD}$, Rodriguez AB. A jerte valley cherry product provides beneficial effects on sleep quality. Influence on aging. J Nutr Health Aging. 2013;17(6):553-60.

133. Garrido M, Paredes SD, Cubero J, Lozano M, Toribio-Delgado AF, Munoz JL, et al. Jerte Valley cherry-enriched diets improve nocturnal rest and increase 6-sulfatoxymelatonin and total antioxidant capacity in the urine of middle-aged and elderly humans. J Gerontol Ser A Biol Sci Med Sci. 2010;65(9):909-14.

134. Kennaway DJ. Are the proposed benefits of melatonin-rich foods too hard to swallow? Crit Rev Food Sci Nutr. 2017;57(5):958-62.

135. Jana $S$, Rastogi $H$. Effects of caffeic acid and quercetin on in vitro permeability, metabolism and in vivo pharmacokinetics of melatonin in rats: potential for herb-drug interaction. Eur J Drug Metab Pharmacokinet. 2017;42(5):781-91.

136. Ives SJ, Bloom S, Matias A, Morrow N, Martins N, Roh Y, et al. Effects of a combined protein and antioxidant supplement on recovery of muscle function and soreness following eccentric exercise. J Int Soc Sports Nutr. 2017;14:21. 
137. Tressera-Rimbau A, Arranz S, Eder M, Vallverdu-Queralt A. Dietary polyphenols in the prevention of stroke. Oxidative Med Cell Longev. 2017;2017:7467962.

138. Manach C, Williamson G, Morand C, Scalbert A, Remesy C. Bioavailability and bioefficacy of polyphenols in humans. I. Review of 97 bioavailability studies. Am J Clin Nutr. 2005;81(1):230S-42S.

139. Wang Y, Chung SJ, Song WO, Chun OK. Estimation of daily proanthocyanidin intake and major food sources in the US diet. J Nutr. 2011;141(3):447-52.

140. Close GL, Hamilton DL, Philp A, Burke LM, Morton JP. New strategies in sport nutrition to increase exercise performance. Free Radic Biol Med. 2016;98:144-58.

141. Yfanti C, Akerstrom T, Nielsen S, Nielsen AR, Mounier R, Mortensen $\mathrm{OH}$, et al. Antioxidant supplementation does not alter endurance training adaptation. Med Sci Sports Exerc. 2010;42(7):1388-95.

142. Merry TL, Ristow M. Do antioxidant supplements interfere with skeletal muscle adaptation to exercise training? J Physiol. 2016;594(18):5135-47.

143. Nogueira L, Ramirez-Sanchez I, Perkins GA, Murphy A, Taub PR, Ceballos G, et al. (-)-Epicatechin enhances fatigue resistance and oxidative capacity in mouse muscle. J Physiol. 2011;589(18):4615-31.
144. Gliemann L, Schmidt JF, Olesen J, Bienso RS, Peronard SL, Grandjean SU, et al. Resveratrol blunts the positive effects of exercise training on cardiovascular health in aged men. J Physiol. 2013;591(20):5047-59.

145. Gliemann L, Olesen J, Bienso RS, Schmidt JF, Akerstrom T, Nyberg M, et al. Resveratrol modulates the angiogenic response to exercise training in skeletal muscles of aged men. Am J Physiol. 2014;307(8):H1111-9.

146. Olesen J, Gliemann L, Bienso R, Schmidt J, Hellsten Y, Pilegaard $\mathrm{H}$. Exercise training, but not resveratrol, improves metabolic and inflammatory status in skeletal muscle of aged men. J Physiol. 2014;592(8):1873-86.

147. Scribbans TD, Ma JK, Edgett BA, Vorobej KA, Mitchell AS, Zelt JGE, et al. Resveratrol supplementation does not augment performance adaptations or fibre-type-specific responses to highintensity interval training in humans. Appl Physiol Nutr Metab. 2014;39(11):1305-13.

148. Romain C, Freitas TT, Martinez-Noguera FJ, Laurent C, Gaillet S, Chung LH, et al. Supplementation with a polyphenol-rich extract, TensLess $((\mathrm{R}))$, attenuates delayed onset muscle soreness and improves muscle recovery from damages after eccentric exercise. Phytother Res. 2017;31(11):1739-46. 